\title{
A Synthetic Material to Simulate Soft Rocks and Its Applications for Model Studies of Socketed Piles
}

\author{
Can Mei, ${ }^{1,2}$ Qing Fang, ${ }^{3}$ Haowei Luo, ${ }^{4}$ Jiangang Yin, ${ }^{5}$ and Xudong Fu ${ }^{1}$ \\ ${ }^{1}$ School of Civil Engineering, Wuhan University, Wuhan 430072, China \\ ${ }^{2}$ China Railway 11th Bureau Group City Rail Engineering Co., Ltd., Wuhan 430000, China \\ ${ }^{3}$ POWERCHINA Hubei Electric Engineering Corporation, Wuhan 430040, China \\ ${ }^{4}$ Northwest Research Institute Co., Ltd., China Railway Engineering Corporation, Lanzhou 730000, China \\ ${ }^{5}$ State Grid Hubei Electric Power Company, Wuhan 430077, China
}

Correspondence should be addressed to Xudong Fu; xdfu@whu.edu.cn

Received 9 March 2017; Revised 11 July 2017; Accepted 7 August 2017; Published 5 December 2017

Academic Editor: Andrey E. Miroshnichenko

Copyright (C) 2017 Can Mei et al. This is an open access article distributed under the Creative Commons Attribution License, which permits unrestricted use, distribution, and reproduction in any medium, provided the original work is properly cited.

\begin{abstract}
A detailed manufacturing procedure of a synthetic soft rock is presented, as well as its applications on the laboratory experiments of socketed piles. With the homogeneity and isotropy of the simulated soft rock, the influence of different variables on the bearing performance could be investigated independently. The constituents, cement, gypsum powder, river sand, concrete-hardening accelerator, and water, were mixed to form the specimens. Both uniaxial and triaxial compressive tests were conducted to investigate the stress-strain behavior of the simulated soft rock. Additionally, the simulated soft rock specimens were used in model pile tests and simple shear tests of the pile-rock interface. Results of the simulated soft rock in both the uniaxial and triaxial compressive tests are consistent with those of natural soft rocks. The concrete-hardening accelerator added to the mixtures improves the efficiency in laboratory investigations of soft rock specimens with a curing time of 7 days. The similarities between the laboratory tests and the field observations provide convincing evidence to support its suitability in modeling the behavior of soft rocks.
\end{abstract}

\section{Introduction}

Physical models have served important functions in geotechnical engineering research and practice, which can clearly portray complex, nonlinear geotechnical mechanisms and phenomena with economic feasibility. In the laboratory physical modeling for geotechnical engineering, the variables and the testing conditions can be controlled easily, and thus a quantitative rule is obtained for the research objects. In the design of physical models, the most important thing is the manufacture of model materials. With regard to model materials to simulate soft rock, the majority of past work has mainly been concerned with mixtures of cement and fine aggregates such as sand or kaolin (e.g., [1-3]). Stimpson [4] has given a comprehensive review of synthetic rock modeling approaches, and materials such as concrete, plaster, cork, rubber, plastics, and gelatins have been particularly useful for producing models of homogenous rock masses, including $1 \mathrm{~g}$ laboratory experiments and centrifuge tests. Indraratna [2] has made excellent general guidelines for the selection of an appropriated model materials-their constituents should be universally obtainable and nontoxic; the mechanical properties of specimens must be identical to one another and easily prepared under laboratory conditions; the physical properties of the simulated soft rock have to be insensitive to heat and humidity; the strength and deformation properties of the simulated rock must satisfy the mechanical scaling criteria.

Johnston and Choi [1] have described the use of crushed mudstone, cement, calcium chloride, and water to manufacture a material that would simulate the consolidation behavior of the naturally occurring mudstone, with a curing time of 15 days. By contrast, Indraratna [2] has used Hydrocal white gypsum cement, fine uniform sand, water, and anhydrous sodium phosphate to simulate soft sedimentary rocks, with a curing time of 28 days. In this study, the simulated soft rock consists of gypsum powder, river sand, concrete-hardening accelerator, and water, and it can be prepared and cured with 7 days before the testing schedule. The techniques of 


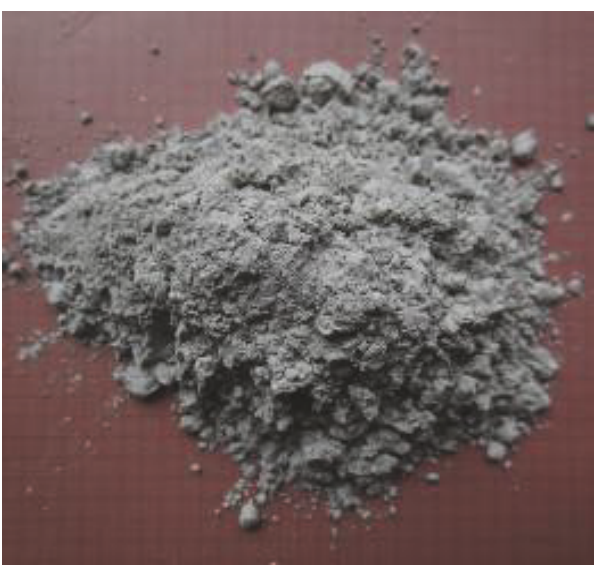

(a)

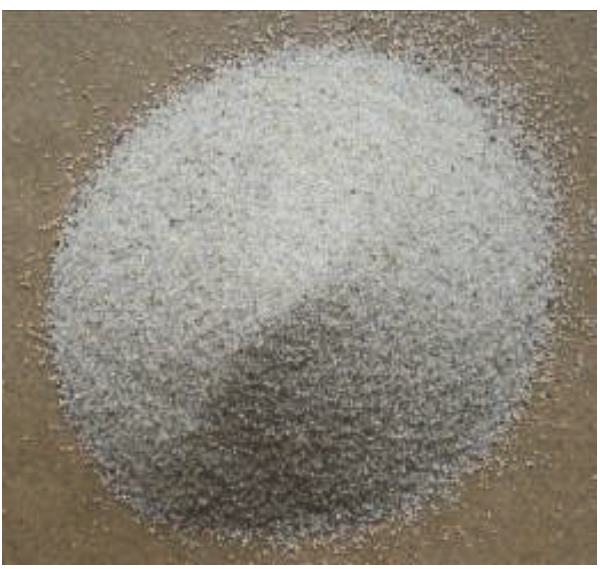

(c)

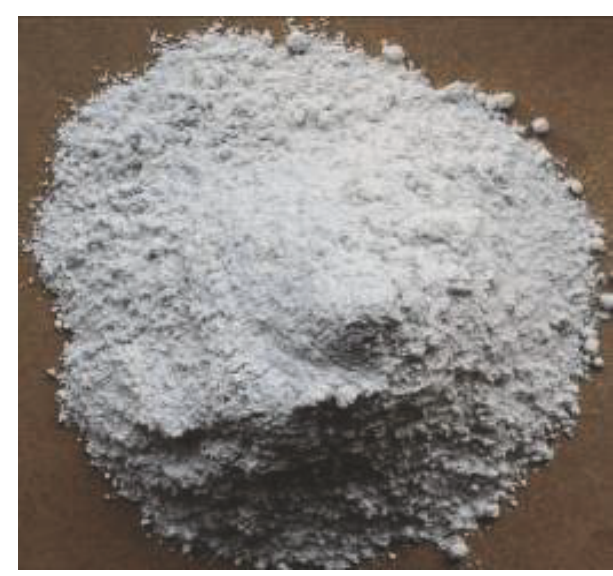

(b)

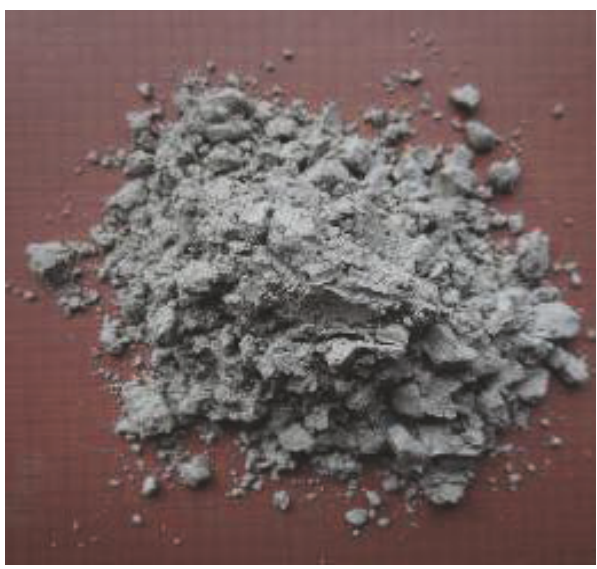

(d)

FIGURE 1: Constituents of simulated soft rocks: (a) cement; (b) plaster; (c) medium sand; (d) concrete-hardening accelerator.

manufacturing the simulated soft rock were presented as well as its applications for the research of drilled piles in soft rocks.

\section{Synthetic Materials of Soft Rocks}

Soft rock is part of the continuous spectrum of materials with strength properties that are intermediate between soil and rock. Soft rocks are harder, more brittle, more dilatant, and more discontinuous than soil. But soft rock is also softer, less brittle, more compressible, and more susceptible to changes induced by variations in effective stress than other types of rock. There are many different criteria to define soft rock: criteria for strengthen deformability, durability, weathering degradation strength-stress relationship, and so forth. Finally it seems that an agreement has been reached between major international associations (ISRM, IAEG, and ISSMGE) and researchers to use the simple compressive strength as a criterion to separate soft rocks from hard soils at the lower limit and from hard rocks at its upper limit. The simple compressive strength is a property commonly used by professionals involved in the design of engineering projects, and in practice, soft rocks will commonly display uniaxial compressive strengths in the range of $0.6 \sim 12.5 \mathrm{MPa}$ and mass stiffness values of 100 1000 MPa [5]. However, in order to collect more data for clarifying the reasonability of the simulated soft rock, the upper limit of the strength of what is considered soft is about $25 \mathrm{MPa}$ as unconfined compressive strength.

2.1. Constituents of the Simulated Soft Rocks. Drawing on previous research in the literature, mixtures containing the following materials were used to form synthetic soft rock in this study: Portland Cement P.C32.5, Duo-bang highstrength gypsum powder, river sand with a maximum grain diameter of $1.00 \mathrm{~mm}$, concrete-hardening accelerator, and water. These materials (shown in Figure 1) are commonly used in the related research of geotechnical engineering and economically obtained. The grain size distribution of the river sand is shown in Figure 2. As indicated by the grading curve in Figure 2, the medium river sand is characterized by $D_{10}$, $D_{50}$, and $D_{60}$ values of $0.113 \mathrm{~mm}, 0.232 \mathrm{~mm}$, and $0.289 \mathrm{~mm}$, respectively.

2.2. Manufacturing and Curing. A specified quantity (see Table 1) of cement, plaster, medium sand, and concretehardening accelerator were put into a blender and mixed. After the dry constituents were mixed overall, an amount of water was added to the mixtures and thoroughly remixed. 
TABLE 1: UCS testing programs and results.

\begin{tabular}{|c|c|c|c|c|c|c|c|c|c|}
\hline Number & $\begin{array}{c}\text { Cement } \\
(\%) \\
\end{array}$ & $\begin{array}{c}\text { Plaster } \\
(\%) \\
\end{array}$ & $\begin{array}{c}\text { Water-cement } \\
\text { ratio }\end{array}$ & $\begin{array}{l}\text { Sand } \\
(\%) \\
\end{array}$ & $\begin{array}{c}\text { Hardening } \\
\text { accelerator } \\
(\%) \\
\end{array}$ & $\begin{array}{l}\text { Density } \\
\left(\mathrm{g} / \mathrm{cm}^{3}\right) \\
\end{array}$ & $\begin{array}{l}\text { Curing time } \\
\text { (d) }\end{array}$ & $\begin{array}{c}\text { Average UCS } \\
\text { value } \\
(\mathrm{MPa})\end{array}$ & $\begin{array}{c}\text { Average } \\
\text { deformation } \\
\text { modulus } \\
(\mathrm{MPa}) \\
\end{array}$ \\
\hline $\mathrm{A} 1$ & 6.0 & 5.0 & 0.50 & 82.12 & 1.38 & 1.70 & 7 & 1.12 & 158.62 \\
\hline A2 & 6.0 & 5.0 & 0.50 & 82.12 & 1.38 & 1.75 & 7 & 1.56 & 204.60 \\
\hline A3 & 6.0 & 5.0 & 0.50 & 82.12 & 1.38 & 1.80 & 7 & 1.97 & 283.91 \\
\hline A4 & 6.0 & 5.0 & 0.50 & 82.12 & 1.38 & 1.85 & 7 & 2.56 & 378.97 \\
\hline A5 & 6.0 & 5.0 & 0.50 & 82.12 & 1.38 & 1.90 & 7 & 3.00 & 428.85 \\
\hline A6 & 6.0 & 5.0 & 0.50 & 82.12 & 1.38 & 1.95 & 7 & 3.43 & 471.38 \\
\hline B1 & 4.5 & 5.0 & 0.50 & 84.71 & 1.04 & 1.80 & 3 & 1.08 & 107.50 \\
\hline B2 & 4.5 & 5.0 & 0.50 & 84.71 & 1.04 & 1.80 & 5 & 1.22 & 138.80 \\
\hline B3 & 4.5 & 5.0 & 0.50 & 84.71 & 1.04 & 1.80 & 14 & 1.62 & 204.64 \\
\hline B4 & 4.5 & 5.0 & 0.50 & 84.71 & 1.04 & 1.80 & 21 & 1.70 & 219.56 \\
\hline B5 & 6.0 & 5.0 & 0.50 & 82.12 & 1.38 & 1.95 & 3 & 2.33 & 336.85 \\
\hline B6 & 6.0 & 5.0 & 0.50 & 82.12 & 1.38 & 1.95 & 5 & 2.95 & 407.23 \\
\hline B7 & 6.0 & 5.0 & 0.50 & 82.12 & 1.38 & 1.95 & 14 & 3.63 & 496.99 \\
\hline B8 & 6.0 & 5.0 & 0.50 & 82.12 & 1.38 & 1.95 & 21 & 3.80 & 522.17 \\
\hline $\mathrm{C} 1$ & 4.5 & 5.0 & 0.50 & 84.71 & 1.04 & 1.80 & 7 & 1.44 & 157.88 \\
\hline $\mathrm{C} 2$ & 6.0 & 5.0 & 0.50 & 82.12 & 1.38 & 1.80 & 7 & 1.74 & 237.90 \\
\hline C3 & 8.0 & 5.0 & 0.50 & 78.66 & 1.84 & 1.80 & 7 & 2.62 & 375.71 \\
\hline $\mathrm{C} 4$ & 11.0 & 5.0 & 0.50 & 73.47 & 2.53 & 1.80 & 7 & 3.37 & 442.15 \\
\hline C5 & 14.0 & 5.0 & 0.50 & 68.28 & 3.22 & 1.80 & 7 & 3.72 & 560.08 \\
\hline D1 & 4.5 & 3.0 & 0.50 & 87.71 & 1.04 & 1.80 & 7 & 1.22 & 211.32 \\
\hline D2 & 4.5 & 8.0 & 0.50 & 80.21 & 1.04 & 1.80 & 7 & 1.52 & 256.99 \\
\hline D3 & 4.5 & 11.0 & 0.50 & 75.71 & 1.04 & 1.80 & 7 & 1.61 & 273.64 \\
\hline D4 & 4.5 & 14.0 & 0.50 & 71.21 & 1.04 & 1.80 & 7 & 1.84 & 312.89 \\
\hline E1 & 4.5 & 5.0 & 0.35 & 86.135 & 1.04 & 1.80 & 7 & 0.85 & 148.56 \\
\hline E2 & 4.5 & 5.0 & 0.43 & 85.375 & 1.04 & 1.80 & 7 & 1.02 & 186.18 \\
\hline E3 & 4.5 & 5.0 & 0.58 & 83.95 & 1.04 & 1.80 & 7 & 1.57 & 254.22 \\
\hline $\mathrm{E} 4$ & 4.5 & 5.0 & 0.65 & 83.285 & 1.04 & 1.80 & 7 & 1.48 & 219.09 \\
\hline $\mathrm{F} 1$ & 4.5 & 5.0 & 0.50 & 85.75 & 0.00 & 1.80 & 7 & 1.41 & 188.39 \\
\hline F2 & 4.5 & 5.0 & 0.50 & 85.3 & 0.45 & 1.80 & 7 & 1.39 & 201.22 \\
\hline F3 & 4.5 & 5.0 & 0.50 & 84.85 & 0.90 & 1.80 & 7 & 1.53 & 224.98 \\
\hline $\mathrm{F} 4$ & 4.5 & 5.0 & 0.50 & 84.53 & 1.22 & 1.80 & 7 & 1.62 & 199.23 \\
\hline F5 & 4.5 & 5.0 & 0.50 & 84.4 & 1.35 & 1.80 & 7 & 1.53 & 208.34 \\
\hline
\end{tabular}

Note. The quantities are proportions by weight. The water-cement ratio refers to the water/(cement + plaster) value.

The samples with a diameter of $50 \mathrm{~mm}$ and a length of $100 \mathrm{~mm}$ were manufactured in three layers. A mould was used to manufacture cylindrical specimens of high precision. A film of lubricating oil was smeared on the inner copper mould before compaction, which was beneficial to demould. The height before and after compaction must be strictly controlled to ensure the homogeneity in the compaction process. The surface of each layer must be shaved to enhance the cementing action in each layer. When the compression stage had been completed, the moulds were removed and the specimens were put into a moisture chamber for curing with 7 days before being tested.

\subsection{Mechanical Properties}

2.3.1. Uniaxial Compressive Tests. Taking several key factors that affect the uniaxial compressive strength of analogue soft rock samples into consideration-such as density, curing time, cement content, plaster content, water-cement ratio, and concrete-hardening accelerator content-uniaxial compressive tests were conducted on 124 specimens with 32 different sets of properties, as shown in Table 1. The typical stressstain behavior of selected specimens is shown in Figure 3. The mixtures with different properties had a uniaxial compressive strength of $0.85 \sim 3.80 \mathrm{MPa}$, and the deformation modulus and 


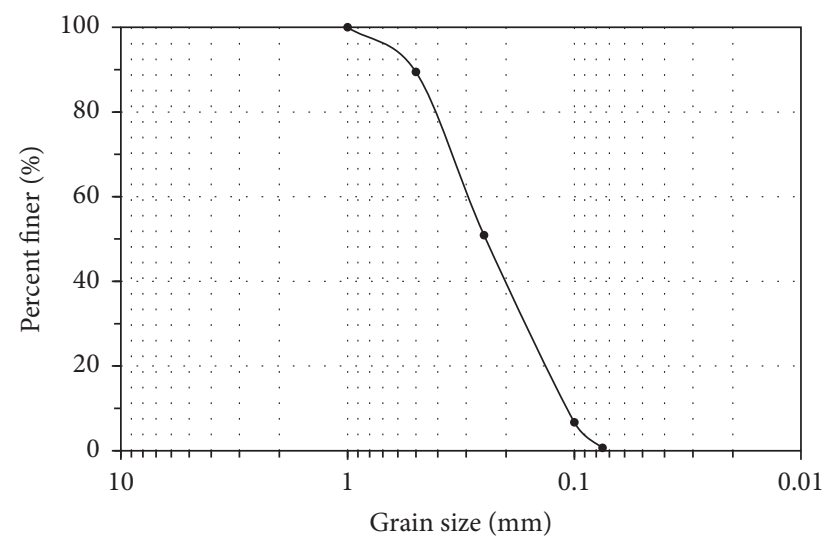

FIGURE 2: Grading curve of the medium river sand.

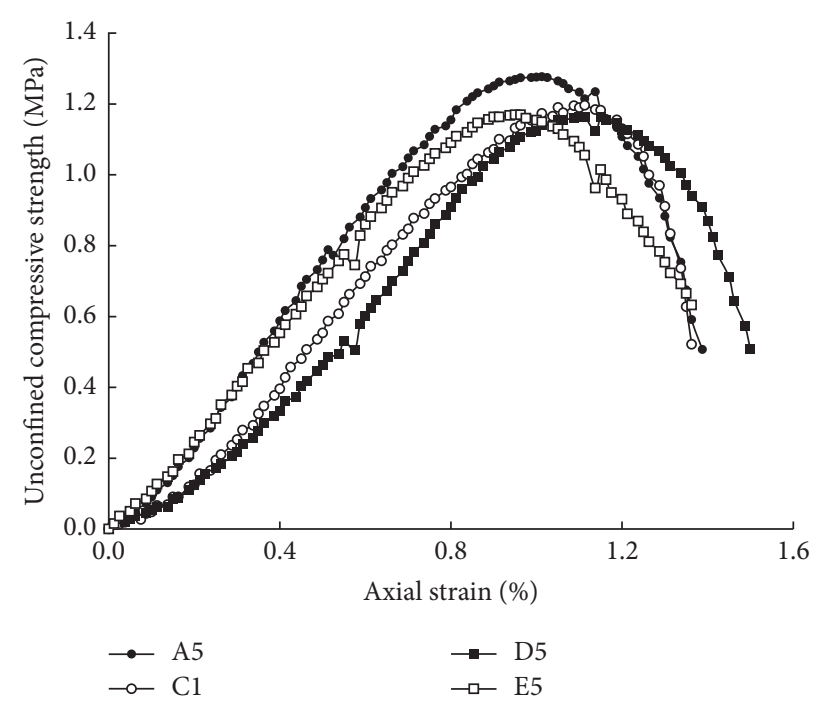

Figure 3: Typical stress-strain curve of simulated soft rock in uniaxial compression.

failure stain were in the range $107.50 \sim 560.08 \mathrm{MPa}$ and $0.8 \%$ $1.3 \%$, respectively.

The relationship between the deformation modulus at $50 \%$ of the ultimate strength $\left(E_{50}\right)$ and the uniaxial compressive strength (UCS) was utilized for the basic description of the rock mechanical properties. Figure 4 displays the variation in the deformation modulus with uniaxial compressive strength for natural soft rock as observed in previous studies and in this study of simulated soft rocks. As seen in Figure 4, the relationship between uniaxial compressive strength and the deformation modulus of simulated soft rock falls into the range seen in natural soft rocks. Meanwhile, in uniaxial compressive tests, the failure strain of the simulated rock is in the range of $0.8 \% \sim 1.3 \%$, which is almost consistent with the observations of natural rocks by Abu-Hejleh et al. [6], that is, $0.9 \% \sim 3.7 \%$. For most of the natural rocks, the strain in the compaction stage varies in a relatively large range and accounts much for the failure strain. However, the homogeneity of simulated soft rocks may have a lot of benefits to obtain the quantitative relationship with little scatter.

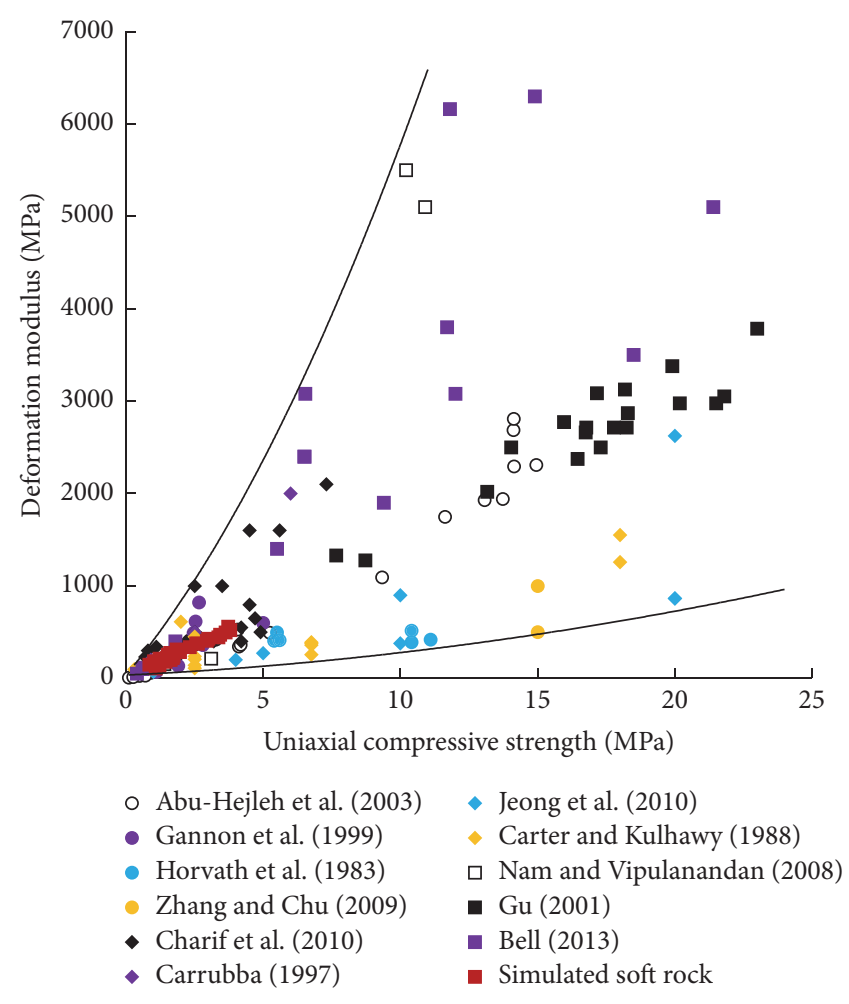

FIGURE 4: Relationship between the deformation modulus and uniaxial compressive strength of simulated soft rock in this study and previous studies (data from [5-15]).

Obviously, the behavior of the simulated soft rock is highly dependent on density, cement content, plaster content, water-cement ratio, concrete-hardening content, and curing time, as indicated in Table 1. The uniaxial compressive strength and defamation modulus of simulated soft rocks increased with increasing of density, cement content, and plaster content. For the limitation of space, only the important factor of the curing time was discussed in this section.

Figures 5(a) and 5(b) show the variations in uniaxial compressive strength and defamation modulus with the time of curing. It was found that the uniaxial compressive strength and defamation modulus increased significantly before the first 7 days and then increased slowly. Additionally, the density of specimens increased with increasing of the compaction energy. The specimens with the density larger than $1.86 \mathrm{~g} / \mathrm{cm}^{3}$ were difficult to be sharped using the light compaction hammer. However, the poor homogeneity would occur with too much lower compaction energy on the specimens. In terms of efficiency and performance, it is recommended that a curing time of 7 days and a density of $1.8 \mathrm{~g} / \mathrm{cm}^{3}$ are suitable for the model testing practice.

2.3.2. Triaxial Compressive Tests. To achieve a comprehensive understanding of the properties of this simulated soft rock, cylindrical specimens $(101 \mathrm{~mm} \times 200 \mathrm{~mm})$ with proportions of cement, plaster, medium sand, water, and concretehardening accelerator of $4.5 \%, 5.0 \%, 84.71 \%, 4.75 \%$, and $1.04 \%$, respectively, were used in triaxial compressive tests at 


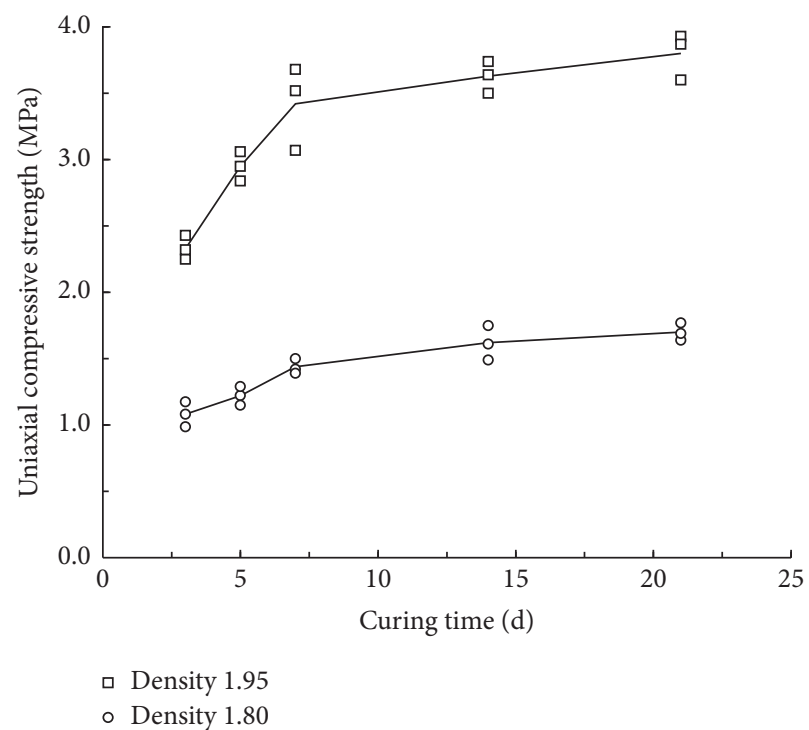

(a)

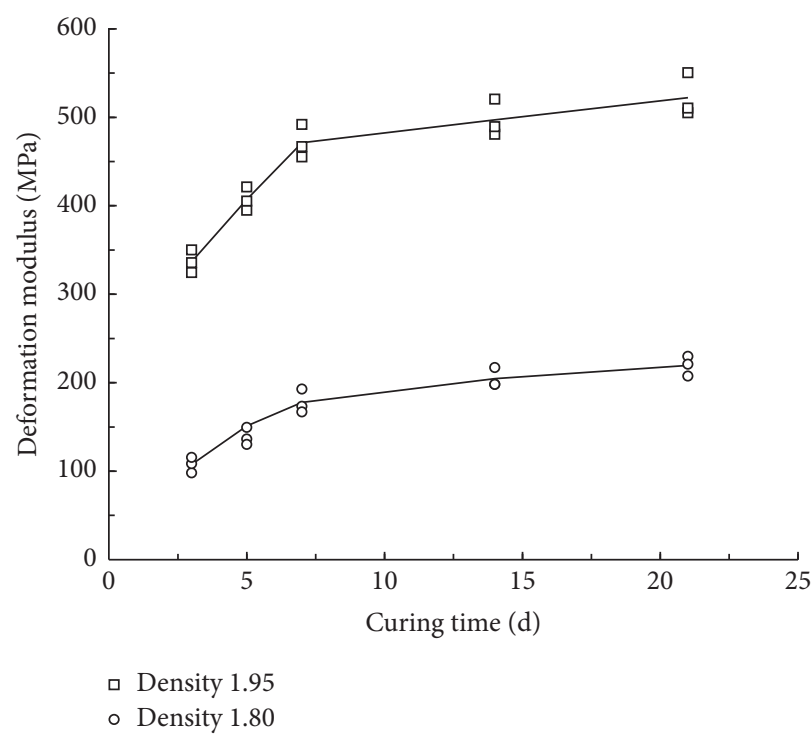

(b)

FIGURE 5: The variation of parameters against curing time: (a) uniaxial compressive strength; (b) deformation modulus.

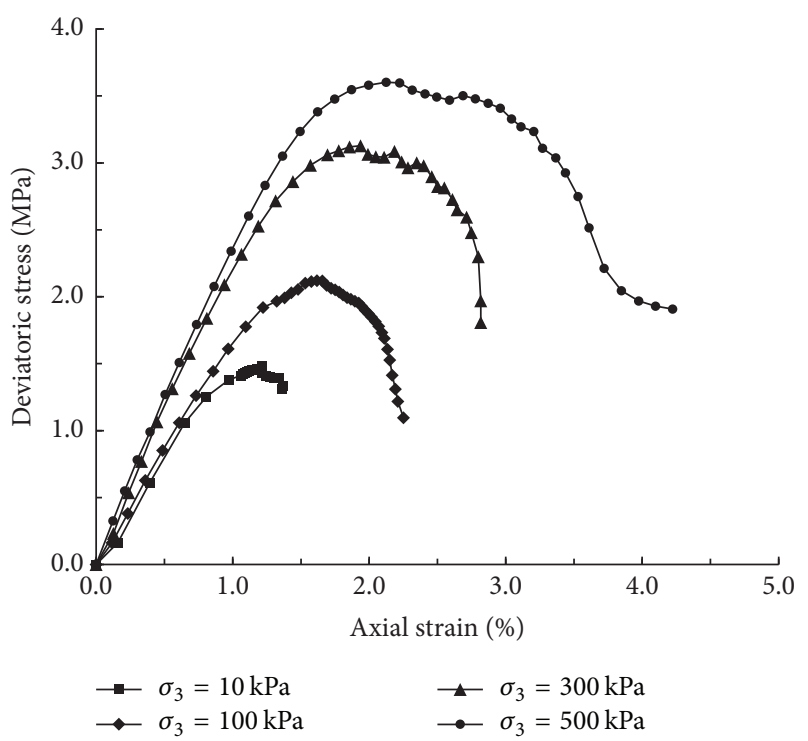

(a)

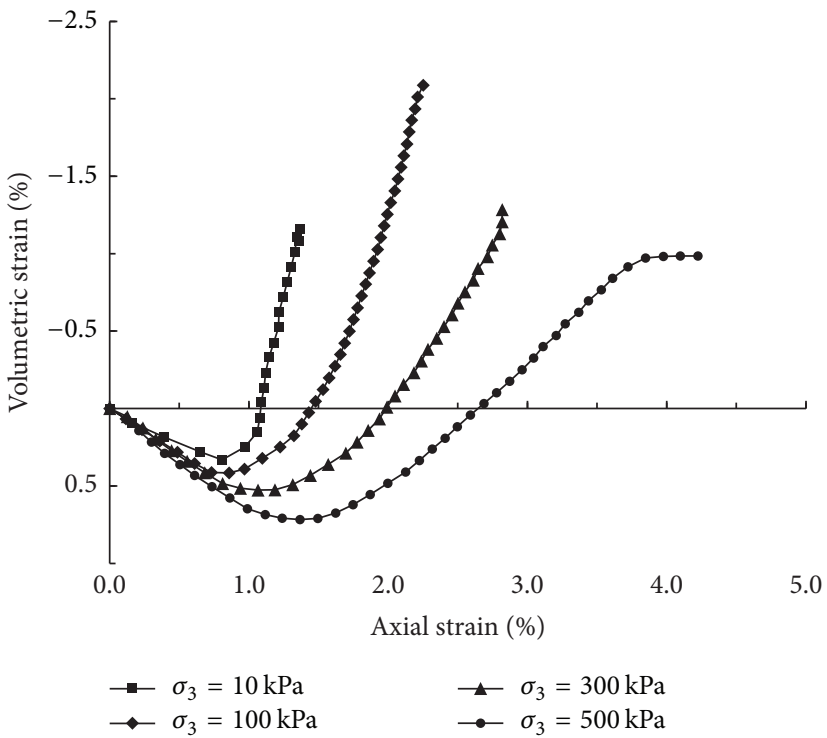

(b)

FiguRE 6: Behavior of the simulated soft rock specimen in triaxial compressive tests: (a) stress-strain curves; (b) volumetric strain-strain curves.

confining stresses varying from $10 \mathrm{kPa}$ to $500 \mathrm{kPa}$. Specimens with a density of $1.8 \mathrm{~g} / \mathrm{cm}^{3}$ and a curing time of 7 days were prepared. After the uniaxial compression tests, the average uniaxial compressive strength was $1.44 \mathrm{MPa}$. Figures 6(a) and 6(b) show the deviator stress and volumetric strain against the axial strain as observed in the triaxial compressive tests. It was shown that the peak deviator stress and deformation modulus increase with increasing confining stresses. The compressive strength and elastic modulus were in the ranges of 1.51 3.61 MPa and 162.16 243.34 MPa, respectively. The maximum axial strain was in the range of $1.13 \% \sim 2.19 \%$. Mohr's circles at the peak effective stress (failure) are illustrated in Figure 7. The Mohr-Coulomb envelopes of the simulated soft rock appears to be linear, with a friction angle of $43.40^{\circ}$ and a cohesion intercept of $0.34 \mathrm{MPa}$.

The Hoek-Brown failure criterion of simulated soft rock and natural rocks are presented in Figure 8, where the principal stresses at failure are normalized by the uniaxial compressive strength. Figure 8 illustrates this relationship for the simulated soft rock samples in this study among a range of different rock types. In addition, the Mohr-Coulomb strength parameters of friction angle of $43.40^{\circ}$ and cohesion intercept 


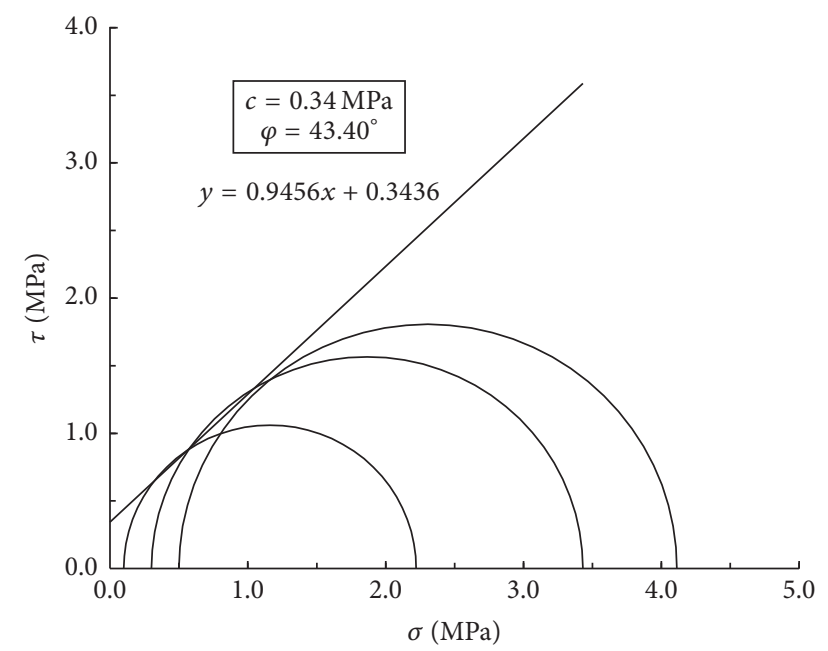

Figure 7: Mohr's circles and strength envelope of the simulated soft rock.

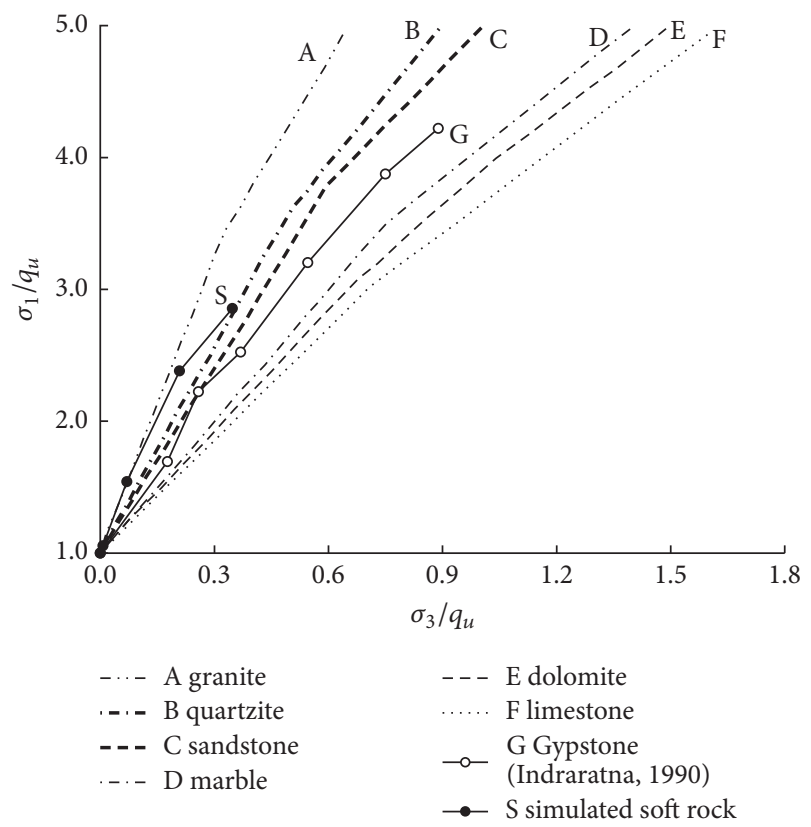

FIGURE 8: Hoek-Brown failure representation of simulated soft rock and various rocks (data from $[2,16]$ ).

of $0.34 \mathrm{MPa}$ were in the range of $13^{\circ} \sim 53^{\circ}$ and $0.1 \sim 2.5 \mathrm{MPa}$ which were collected and sorted from the natural soft rocks in the literature published previously [5-15].

Based on the factors discussed above, it was found that the strength and deformation properties of the simulated soft rock in both uniaxial and triaxial compression tests were consistent with those of natural rocks. In addition, the constituents are universally and economically obtainable. Moreover, the specimens can be shaped and cured easily. As a consequence, the analogue material and its manufacturing method can be used to simulate soft rock in model experiments. However, the simulated materials may have a little difficulty in simulating the fissures, joints, structural surfaces, discontinuities, and stress history of the actual rocks since they are found to be homogeneous and isotropic. And the small laboratory specimens are also not representative of the actual field behavior, which is influenced by a much larger scale effect.

\section{Experimental Applications of the Simulated Soft Rocks}

On the basis of the reasonability of simulated soft rock, these materials and manufacturing techniques have be used in the investigations of socketed piles in soft rock. Indeed, it can also be used in other research of rock mechanics, such as rock slope and rock tunneling. In this section, the experimental applications of the simulated soft rock in socketed piles are discussed briefly and other details of the applications are presented by Huang [17].

3.1. Investigation of Pile Bearing Performance. The applications of the simulated soft rock included an experimental model study of bearing behavior of piles in soft rock using the apparatus developed by our team, as detailed in Figure 9. It aimed to investigate the influences of varying parameters such as the socketed depth, overburden pressure, and pile diameter on the pile bearing capacity.

As a result of these studies, the measured total bearing capacity of piles in soft rock showed a similar relationship and varying tendency compared to the calculated result using the spherical cavity expansion theory. And the measured shaft resistance increased to a peak and then decreased near the tip of the pile, which was consistent with the results of in situ loading tests [18]. The failure zone of soft rocks beneath the model pile was captured with the aid of CT scanning and it is shown like a shaped deformation bulb, as shown in Figure 10. Additionally, the failure pattern and measured capacities agreed well with the calculation analysis using the spherical cavity expansion theory.

3.2. Investigation of Pile-Rock Interface. The shear behavior of pile-rock interface is a critical factor in the performance of socketed piles in soft rock. Direct and simple shear tests are the two common laboratory testing methods used to investigate the behavior of the pile (concrete)-rock interface. In fact, the measured shear strength parameters using the direct shear tests are overestimated for the limitation of test conditions. Simple shear tests are created as an attempt at improvement over the performance of the direct shear box. Based on the two main types of simple shear devices designed by the Norwegian Geotechnical Institute and by the Cambridge University, an improved simple shear device with rotatable plates was created for minimizing the influence of shear boxes on the sample deformation along the shear direction, as shown in Figure 11.

The simulated soft rock samples were shaped easily with specific surface geometries, and then the samples were tested in the simple shear apparatus against a concrete section simulating the pile under different vertical pressures. It was found that the shear strength of the simulated soft rock samples is higher than the pile-rock interface, suggesting that the failure 


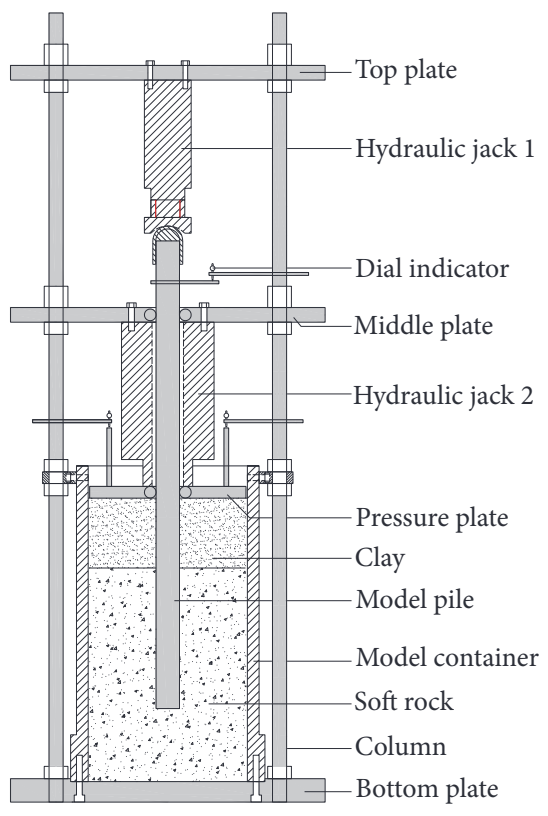

FIGURE 9: Schematic illustration of the model test apparatus.

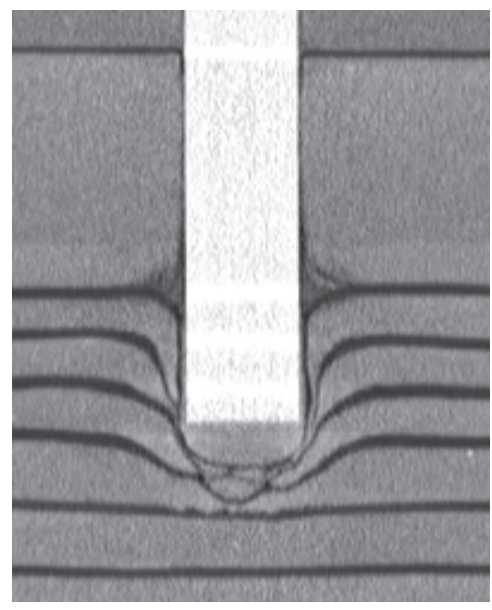

FIGURE 10: Pile tip failure model (settlement/diameter $=1.7)$.

zone of socketed piles may occur in the pile-rock interface under shear progress of loading. The pile-rock interface performance was highly dependent on the level of roughness and normal stress on the contact. Figure 12 shows the roughed concrete section used in the bottom shear box simulating the socketed piles. And Figure 13 displays the failure status of simulated soft rock samples after the loading program, which indicated that the shear failure surfaces almost always occur in the triangular profiles. It was also confirmed that the interface between the piles and the soft rocks was the weaker area easily damaged when the pile was loaded.

\section{Conclusions}

(1) Based on the comparison on mechanical properties of the simulated soft rocks and natural soft rocks in both uniaxial and triaxial compressive tests, these

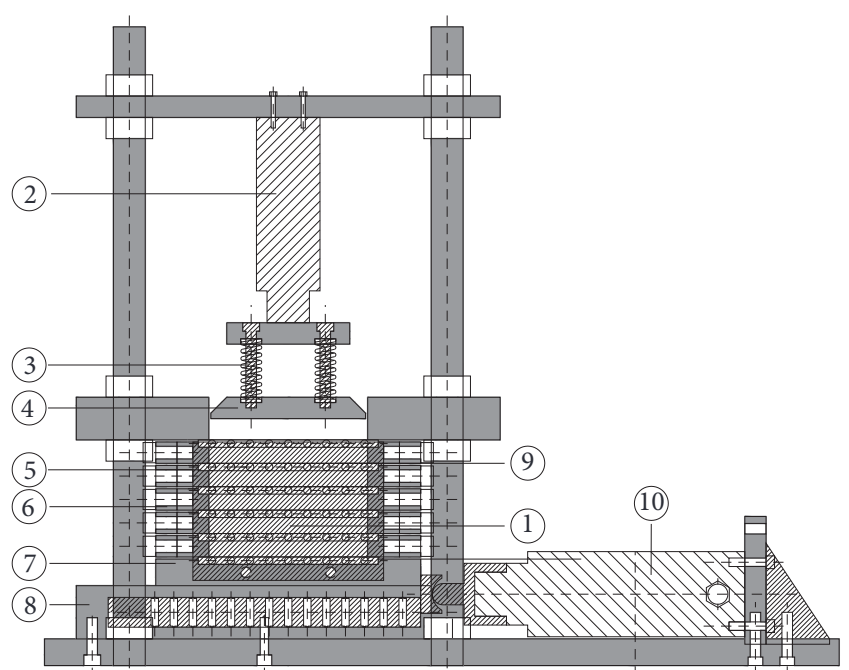
(1) Sample
(2) Hydraulic jack for vertical load
(3) Strong spring
(4) Top platen
(5) Flap

\begin{abstract}
(6) Shear box system
(7) Bottom shear box

(8) Slide guide

(9) Needle roller bearing

(10) Hydraulic jack for horizontal force
\end{abstract}

FIGURE 11: Schematic illustration of the simple shear devices with rotatable plates.

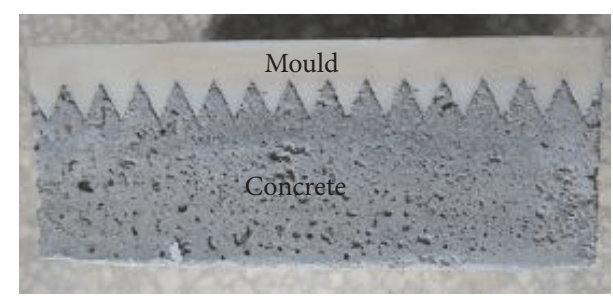

FIGURE 12: Roughness profiles used in simple shear testing.

constituents of cement, gypsum powder, river sand, concrete-hardening accelerator, and water are recommended to simulate the soft rocks with good performances in laboratory investigation. It substantially improves the efficiency of the preparation of specimens with the aid of concrete-hardening accelerator.

(2) The uniaxial compressive strength and deformation modulus of the simulated soft rock are in the range of $0.85 \sim 3.80 \mathrm{MPa}$ and 107.50 560.08 MPa. All these percentages of each constituent and its mechanical parameters could be the reference for the similar rock mechanic problems. In addition, it is reasonable to obtain the simulated soft rocks that those mechanical parameters are beyond the range mentioned above, with the extension of the quantitative relationship of the mechanical parameters and its percentages of constituents.

(3) The applications of the simulated soft rocks to socketed piles are presented, which focus on the loadtransfer mechanisms and bearing performance of 


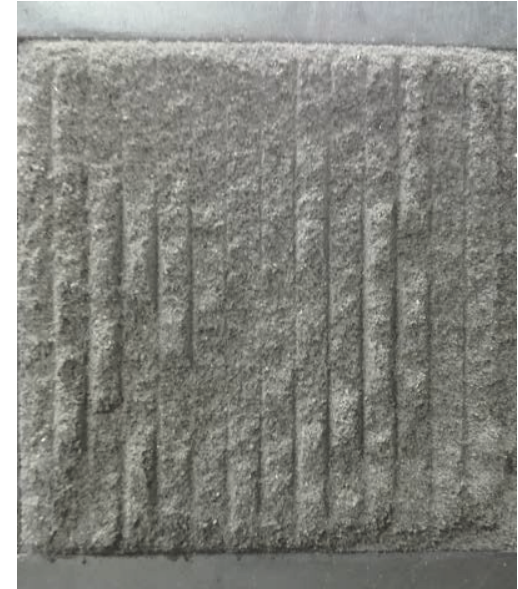

FIGURE 13: Failure status of simulated soft rocks after testing.

piles in soft rock. The homogeneous and isotropic simulated soft rock is manufactured into defined sizes and shapes readily with constant mechanical properties under laboratory conditions.

\section{Conflicts of Interest}

The authors declare that they have no conflicts of interest.

\section{Acknowledgments}

The work described in this paper was supported by the National Natural Science Foundation of China (Grant nos. 51378403 and 51309028) and Ph.D. Short-Time Mobility Program of Wuhan University. The authors thank Benjiao Zhang, Bin Huang, Zifeng Qiu, Lei Xiao, and Gang Luo for their valuable contributions to the model tests. The project has been also supported by POWERCHINA Hubei Electric Engineering Corporation and State Grid Hubei Electric Power Company. Mr. Qing Fang is the senior engineer in charge of technical work of this project. And Mr. Jiangang Yin is the project manager to organize and coordinate this project completely.

\section{References}

[1] I. W. Johnston and S. K. Choi, "A synthetic soft rock for laboratory model studies," Geotechnique, vol. 36, no. 2, pp. 251-263, 1986.

[2] B. Indraratna, "Development and applications of a synthetic material to simulate soft sedimentary rocks," Geotechnique, vol. 40, no. 2, pp. 189-200, 1990.

[3] B. Imre, B. Wildhaber, and S. M. Springman, "A physical analogue material to simulate sturzstroms," International Journal of Physical Modelling in Geotechnics, vol. 11, no. 2, pp. 69-86, 2011.

[4] B. Stimpson, "Modelling materials for engineering rock mechanics," International Journal of Rock Mechanics and Mining Sciences \& Geomechanics Abstracts, vol. 7, no. 1, pp. 77-121, 1970.

[5] J. A. Gannon, G. G. T. Masterton, W. A. Wallace, and D. M. Wood, Piled Foundations in Weak Rock, Construction Industry Research and Information Association, London, UK, 1999.
[6] N. M. Abu-Hejleh, M. W. O’Neill, D. Hanneman, and W. J. Attwooll, "Improvement of the geotechnical axial design methodology for Colorado's drilled shafts socketed in weak rocks," Tech. Rep., Colorado Department of Transportation, Research Branch, Colorado, Colo, USA, 2003.

[7] R. G. Horvath, T. C. Kenney, and P. Kozicki, "Methods of improving the performance of drilled piers in weak rock," Canadian geotechnical journal, vol. 20, no. 4, pp. 758-772, 1983.

[8] L. Zhang and L. F. Chu, "Calibration of methods for designing large-diameter bored piles: ultimate limit state," Soils and Foundations, vol. 49, no. 6, pp. 883-895, 2009.

[9] K. H. Charif, S. S. Najjar, and S. Sadek, "Side friction along drilled shafts in weak carbonate rocks," in Proceedings of the Art of Foundation Engineering Practice Congress 2010, pp. 190-205, West Palm Beach, Fla, USA, February 2010.

[10] P. Carrubba, "Skin friction of large-diameter piles socketed into rock," Canadian Geotechnical Journal, vol. 34, no. 2, pp. 230 240, 1997.

[11] S. Jeong, S. Ahn, and H. Seol, "Shear load transfer characteristics of drilled shafts socketed in rocks," Rock Mechanics and Rock Engineering, vol. 43, no. 1, pp. 41-54, 2010.

[12] J. P. Carter and F. H. Kulhawy, Analysis and Design of Drilled Shaft Foundations Socketed into Rock, Electric Power Research Institute, Palo Alto, Calif, USA, 1988.

[13] M. S. Nam and C. Vipulanandan, "Roughness and unit side resistances of drilled shafts socketed in clay shale and limestone," Journal of Geotechnical and Geoenvironmental Engineering, vol. 134, no. 9, pp. 1272-1279, 2008.

[14] X. F. Gu, Shear Behaviour of Sandstone-Concrete Joints and Pile Shafts in Sandstone, Monash University, Department of Civil Engineering, Victoria, Australia, 2001.

[15] F. G. Bell, Engineering Properties of Soils and Rocks, Elsevier, Amsterdam, Netherlands, 4th edition, 2013.

[16] E. Hoek and E. T. Brown, Underground Excavations in Rock, Institute of Mineralogy and Metallurgy, London, Uk, 1980.

[17] B. Huang, Bearing Mechanisms of Socketed Piles in Soft Rock, Wuhan University, Wuhan, China, 2016.

[18] G. M. Wang, "Load transferring behaviour of drilled piles in soft rocks," Chinese Journal of Geotechnical Engineering, vol. 18, no. 2, pp. 99-103, 1996. 

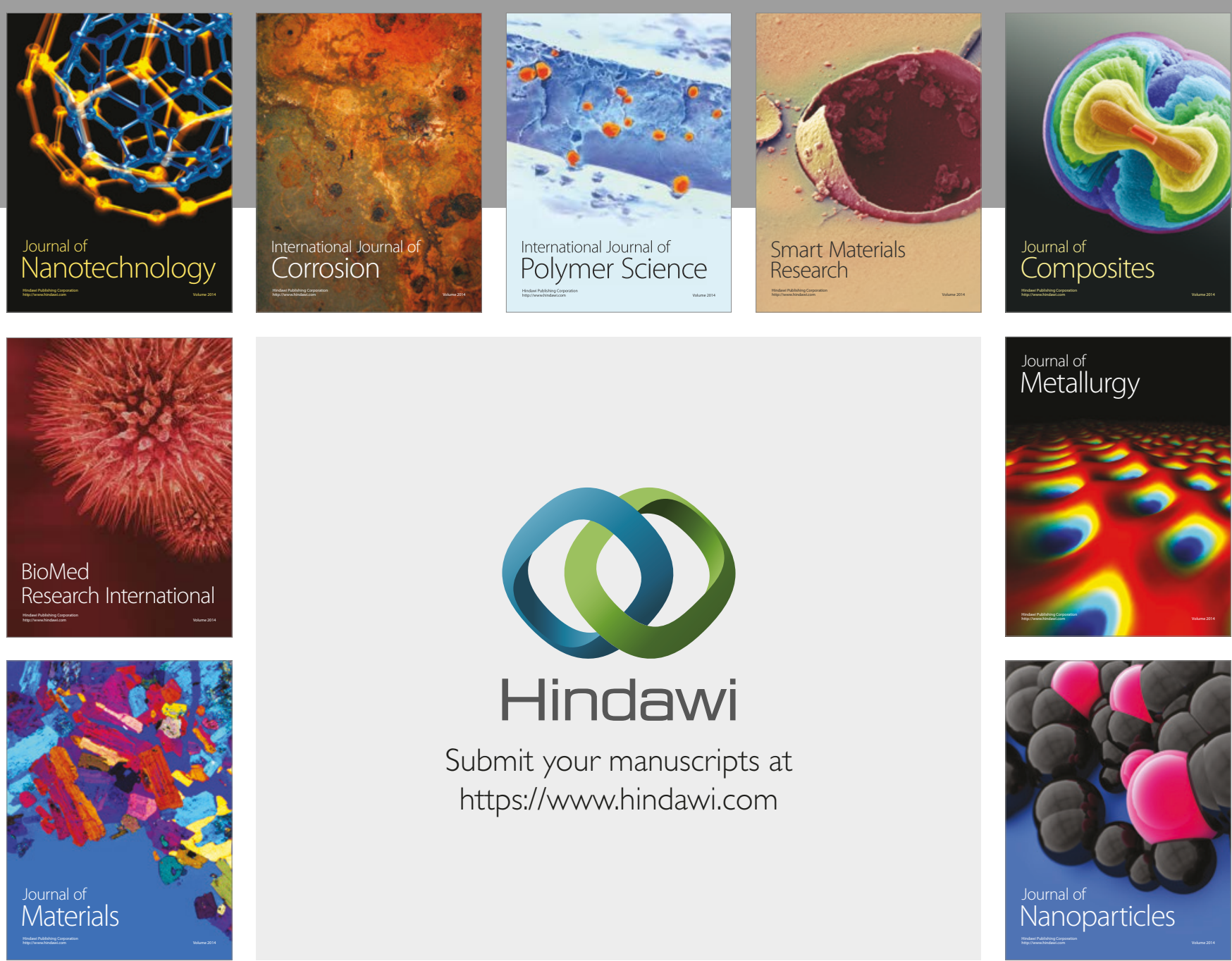

\section{Hindawi}

Submit your manuscripts at

https://www.hindawi.com
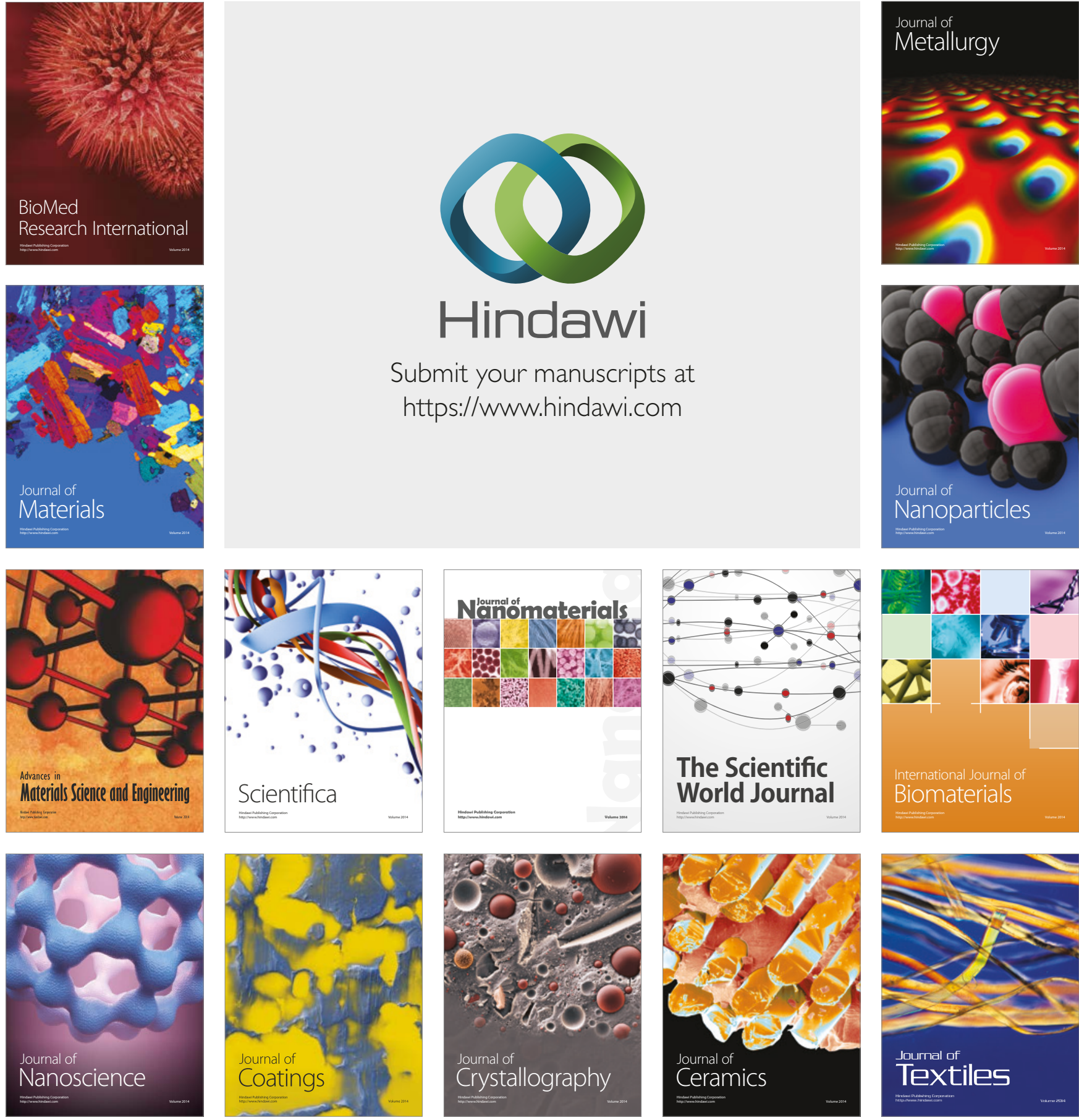

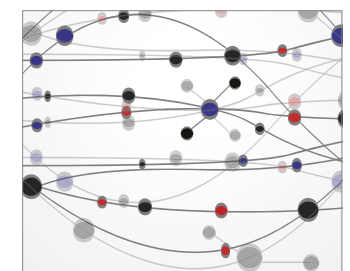

The Scientific World Journal
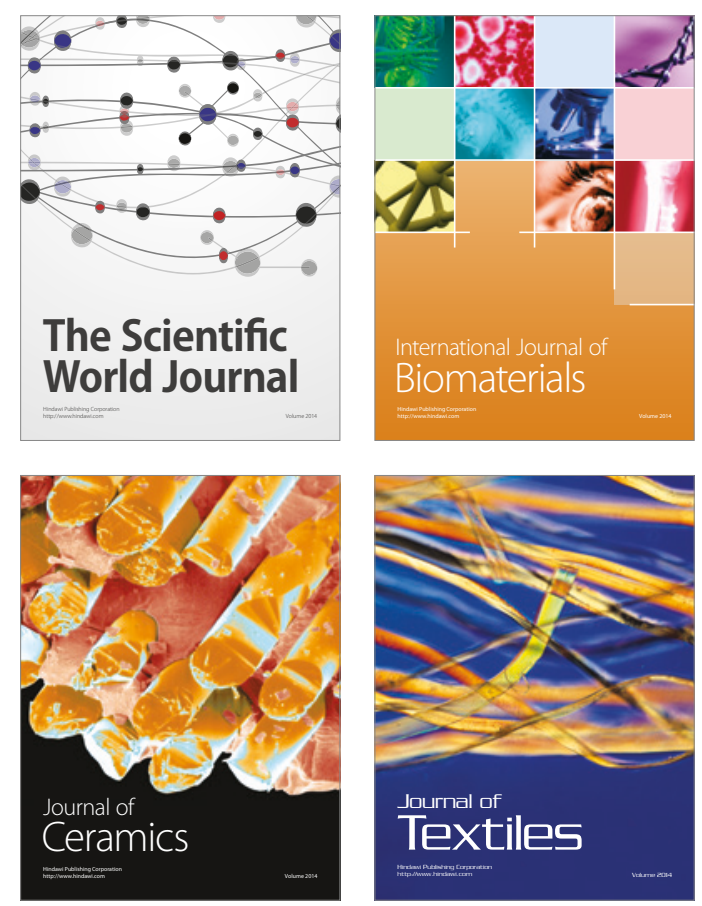